\title{
Risk Perception of Paracetamol Use among Undergraduate Students of University of Jos
}

\author{
Theophilus Monday Ejeikwu, Winna Folashade \\ University of Jos, Jos, Nigeira \\ Email: ejeikwutheophilus@gmail.com
}

How to cite this paper: Ejeikwu, T.M. and Folashade, W. (2019) Risk Perception of Paracetamol Use among Undergraduate Students of University of Jos. Open Access Library Journal, 6: e5810.

https://doi.org/10.4236/oalib.1105810

Received: September 23, 2019

Accepted: October 28, 2019

Published: October 31, 2019

Copyright ( 2019 by author(s) and Open Access Library Inc.

This work is licensed under the Creative

Commons Attribution International

License (CC BY 4.0).

http://creativecommons.org/licenses/by/4.0/

(c) (i) Open Access

\begin{abstract}
The literature is replete with studies on prevalence of paracetamol abuse; however, a paucity of literature on risk perception of paracetamol use especially in Nigeria was discovered by the researcher. This study describes the risk perception of paracetamol use among undergraduate students of the University of Jos, Plateau state, Nigeria. A descriptive research design was used in this study. Recruitment was done by simple random sampling technique and a close-ended questionnaire was employed in collecting the desired data. Frequency distribution tables and percentages were used to present and analyze the data generated while chi-square was used to test the null hypothesis. Almost all participants, $93.1 \%$ had taken paracetamol in their lifetime. Also, $63.6 \%$ of participants said paracetamol is very easy to get and most of them $(49.7 \%)$ had taken paracetamol on 40 or more occasions indicating high prevalence of paracetamol use among them. More than half, $53.6 \%$ of participants do not believe self-medication with paracetamol can harm them. Only $34.9 \%$ of respondents knew the normal maximum daily dose of paracetamol. Also, only $39.5 \%$ of participants knew that combining paracetamol with procold is harmful. Just $25.1 \%$ respondents read the patient information leaflet always before taking paracetamol. Most of them, 73.6\% knew that combining paracetamol intake with alcohol can cause liver failure; however only $23.1 \%$ of them knew that people with liver diseases are not to take paracetamol. A significant relationship existed between courses of study of students and risk perception of paracetamol use. The participants showed poor risk perception of paracetamol use. It was recommended that the federal ministry of health should intensify awareness campaign through the mass media and outreach program to educate the masses on the adverse effects of paracetamol use.
\end{abstract}

\section{Subject Areas}

Pharmacology, Epidemiology 


\section{Keywords}

Risk, Perception, Paracetamol Use, Science Students, Arts Students

\section{Introduction}

Generally, paracetamol is the most widely used over-the-counter (OTC) and prescription analgesic worldwide [1]. According to [2], self-medication has been on the increase and irrational use of the over-the-counter drugs is a cause of serious concern for public health agencies.

Paracetamol is a non-opioid analgesic which finds application in the management of mild pain and fever. It exerts its therapeutic effects by inhibiting the synthesis of prostaglandin (a pain mediator) in the central nervous system [3]. Paracetamol is used in the management of mild to moderate pain such as headache, myalgia (muscle pain), postpartum pain (pain following delivery of a baby), and in other circumstances in which aspirin is an effective analgesic [4].

Paracetamol use is associated with certain adverse effects in spite of the therapeutic effects adumbrated in the preceding paragraph. [4] opined that acute intake of over 150 - $200 \mathrm{mg} / \mathrm{kg}$ (children) or $7 \mathrm{~g}$ total (adults) is considered potentially toxic; in severe cases, fulminant liver failure occurs, leading to hepatic encephalopathy and death. With large doses of paracetamol, patients with hepatic diseases, viral hepatitis, or a history of alcoholism are at higher risk of paracetamol induced hepatotoxicity [3]. [5], in an analysis covering over 130,000 woman found a link between prolonged paracetamol use during pregnancy and a slight rise in the risk of Autism Spectrum Disorder (ASD) and Attention Deficit-Hyperactive Disorder (ADHD) among the babies born to these women. If the recommended doses of paracetamol is exceeded acute liver failure sets in and is the most frequent cause of Acute Liver Failure (ALF) in the United Kingdom, United States, Europe and Australia [1].

It is anticipated that with the advent of internet and the ground breaking improvement in the field of information and communication technologies, paracetamol users will have adequate knowledge regarding the risk associated with over-the-counter paracetamol use; however, the reverse is the case. [6], reported low risk perception and significant prevalence of self-medication among the participants; [7] also reported that, despite the fact that the study population purchase paracetamol mainly over-the-counter, they showed basic awareness of paracetamol use including the potential consequences of overdosing; young adults (18 - 25 years), who use over-the-counter paracetamol frequently perceived less risk associated with use compared with older participants. People think that only safe medicines are legal to be sold without prescription and over-the-counter medicines usually do not have detrimental effects [8]. Virtually all users are not aware of the harmful effects of paracetamol abuse [9]. [1], observed that the narrow therapeutic index of paracetamol makes the normal dose of paracetamol 
close to the overdose, and the fact that it is found in many prescription over-the-counter preparations should prompt users to monitor their intake closely. In a study conducted by [10] on paracetamol use (and/or misuse) in children in Enugu, South-East, Nigeria, it was discovered that paracetamol was commonly administered to children on "self-prescription" basis and the tablet formulation was most often used, with the tendency to misuse and overdose. According to [11], majority of people have no idea of the maximum daily dose of paracetamol.

Considering that a lot of people are still unaware of the adverse effects of paracetamol misuse and the lack of integrated body of knowledge on the risk perception of paracetamol use among educated people in Jos metropolis, this study, therefore, set out to assess the risk perception of paracetamol use among undergraduate students at the University of Jos, Plateau State.

\section{Data Analysis and Interpretation}

Table 1 shows the socio-demographic variables of the participants. More than half $(55.4 \%)$ of the participants were males and $85.9 \%$ of them were Christians. Participants within the age bracket of 26 - 30 years were more in number (39\%), followed by those aged $21-25$ years at $24.4 \%$. More than half of the participants again $(56.7 \%)$ were science students, and $43.3 \%$ were arts and humanity students. Most of the participants (32.6\%) randomly selected were in 400 level.

Table 1. Socio-demographic variables of participants.

\begin{tabular}{|c|c|c|c|c|}
\hline S/No. & Item & & Frequency & Percentage $\%$ \\
\hline \multirow{3}{*}{1.} & Gender & Male & 174 & $44.6 \%$ \\
\hline & & Female & 216 & $55.4 \%$ \\
\hline & Total & & 390 & $100 \%$ \\
\hline \multirow{6}{*}{2.} & Age & $15-20$ years & 43 & $11 \%$ \\
\hline & & $21-25$ years & 95 & $24.4 \%$ \\
\hline & & 26 - 30 years & 152 & $39 \%$ \\
\hline & & 31 - 35 years & 70 & $17.9 \%$ \\
\hline & & 36 years and above & 30 & $7.7 \%$ \\
\hline & Total & & 390 & $100 \%$ \\
\hline \multirow{4}{*}{3.} & What is your religion? & Christianity & 335 & $85.9 \%$ \\
\hline & & Islam & 55 & $14.1 \%$ \\
\hline & & Others & 0 & $0 \%$ \\
\hline & Total & & 390 & $100 \%$ \\
\hline \multirow{3}{*}{4.} & What course are you studying & Science & 221 & $56.7 \%$ \\
\hline & & Arts/humanity & 169 & $43.3 \%$ \\
\hline & Total & & 390 & $100 \%$ \\
\hline \multirow{7}{*}{5.} & What is your current level in & 100 level & 106 & $27.2 \%$ \\
\hline & the university & 200 level & 78 & $20 \%$ \\
\hline & & 300 level & 50 & $12.8 \%$ \\
\hline & & 400level & 127 & $32.6 \%$ \\
\hline & & 500 level & 29 & $7.4 \%$ \\
\hline & & 600 level & 0 & $0 \%$ \\
\hline & Total & & 390 & $100 \%$ \\
\hline
\end{tabular}


Table 2 portrays the prevalence of paracetamol use among the respondents. Almost all the participants (93.1\%) had taken paracetamol in their life time. Only $34.9 \%$ of participants knew the normal maximum daily dose of paracetamol; however, $60.8 \%$ of the participants knew how many times the normal dose of paracetamol should be taken. A significant number of them (30.8\%) said treatment with paracetamol last for three days only. Majority of them (63.6\%) said paracetamol is very easy to get if one desires to have it and $49.7 \%$ of the participants admitted they had taken paracetamol on 40 or more occasion in their life time. Also, $10.3 \%$ of participants were undecided on the question bordering on how many occasions (if any) during their life time they had taken paracetamol and $33.6 \%$ of the students had not taken paracetamol over the last 30 days. Additionally, $32.1 \%$ of the participants last took paracetamol 15 - 30 days ago.

Table 2. Prevalence of paracetamol use among university of Jos undergraduates.

\begin{tabular}{|c|c|c|c|c|}
\hline S/No. & Item & Options & Frequency & Percentage \% \\
\hline \multirow{4}{*}{6} & \multirow{3}{*}{$\begin{array}{c}\text { Have you ever taken p.c.m in } \\
\text { your life? }\end{array}$} & Yes & 363 & $93.1 \%$ \\
\hline & & No & 27 & $6.9 \%$ \\
\hline & & Undecided & 0 & $0 \%$ \\
\hline & Total & & 390 & $100 \%$ \\
\hline \multirow{6}{*}{7} & \multirow{5}{*}{$\begin{array}{l}\text { What is the normal dose of p.c.m } \\
\text { in a day? }\end{array}$} & $4 \mathrm{~g}$ maximum & 136 & $34.9 \%$ \\
\hline & & $5 \mathrm{~g}$ maximum & 80 & $20.5 \%$ \\
\hline & & $6 \mathrm{~g}$ maximum & 59 & $15.1 \%$ \\
\hline & & $7 \mathrm{~g}$ maximum & 0 & $0 \%$ \\
\hline & & Undecided & 115 & $29.5 \%$ \\
\hline & Total & & 390 & $100 \%$ \\
\hline \multirow{6}{*}{8} & \multirow{5}{*}{$\begin{array}{l}\text { How many times should the } \\
\text { normal dose of p.c.m be taken in } \\
\text { a day? }\end{array}$} & 2 times & 153 & $39.2 \%$ \\
\hline & & 3 times & 237 & $60.8 \%$ \\
\hline & & 4 times & 0 & $0 \%$ \\
\hline & & 5 times & 0 & $0 \%$ \\
\hline & & Undecided & 0 & $0 \%$ \\
\hline & Total & & 390 & $100 \%$ \\
\hline \multirow{6}{*}{9} & \multirow{5}{*}{$\begin{array}{l}\text { How long should treatment with } \\
\text { p.c.m last? }\end{array}$} & 1 day only & 106 & $27.2 \%$ \\
\hline & & 2 days only & 64 & $16.4 \%$ \\
\hline & & 3 days only & 120 & $30.8 \%$ \\
\hline & & $\begin{array}{l}\text { As long as other } \\
\text { symptoms persist }\end{array}$ & 57 & $14.1 \%$ \\
\hline & & Undecided & 43 & $11.0 \%$ \\
\hline & Total & & 390 & $100 \%$ \\
\hline \multirow{7}{*}{10} & \multirow{6}{*}{$\begin{array}{c}\text { How difficult do you think it } \\
\text { would be for you to get p.c.m if } \\
\text { you wanted? }\end{array}$} & Impossible & 45 & $11.5 \%$ \\
\hline & & Very difficult & 0 & $0 \%$ \\
\hline & & Fairly difficult & 17 & $4.4 \%$ \\
\hline & & Fairly easy & 80 & $20.5 \%$ \\
\hline & & Very easy & 248 & $63.6 \%$ \\
\hline & & Undecided & 0 & $0 \%$ \\
\hline & Total & & 390 & $100 \%$ \\
\hline
\end{tabular}




\section{Continued}

\begin{tabular}{|c|c|c|c|c|}
\hline \multirow{9}{*}{ 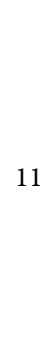 } & \multirow{8}{*}{$\begin{array}{l}\text { On how many occasions (if any) } \\
\text { during your life time have you } \\
\text { taken p.c.m? }\end{array}$} & 0 & 13 & \multirow[t]{2}{*}{$3.3 \%$} \\
\hline & & $1-2$ & 0 & \\
\hline & & $3-5$ & 13 & $3.3 \%$ \\
\hline & & $6-9$ & 20 & $5.1 \%$ \\
\hline & & $10-19$ & 55 & $14.1 \%$ \\
\hline & & $20-39$ & 55 & $14.1 \%$ \\
\hline & & 40 or more & 194 & $49.7 \%$ \\
\hline & & Undecided & 40 & $10.3 \%$ \\
\hline & Total & & 390 & $100 \%$ \\
\hline \multirow{4}{*}{11} & Think back over the last 30 days, & 0 & 131 & $33.6 \%$ \\
\hline & on how many occasions (if any) & $1-2$ & 82 & $21.0 \%$ \\
\hline & have you had p.c.m? & $3-5$ & 69 & $17.7 \%$ \\
\hline & & $6-9$ & 41 & $10.5 \%$ \\
\hline \multirow[t]{8}{*}{12} & & $10-19$ & 20 & $5.1 \%$ \\
\hline & & $20-39$ & 27 & $6.9 \%$ \\
\hline & & 40 or more & 20 & $5.1 \%$ \\
\hline & & Undecided & 0 & $0 \%$ \\
\hline & Total & & 390 & $100 \%$ \\
\hline & When was the last day you took & I never took p.c.m & 21 & $5.4 \%$ \\
\hline & p.c.m? & 1 - 7 days ago & 84 & $21.5 \%$ \\
\hline & & 8 - 14 days ago & 42 & $10.8 \%$ \\
\hline \multirow{5}{*}{13} & & 15 - 30 days ago & 125 & $32.1 \%$ \\
\hline & & 1 month - 1 year ago & 90 & $23.1 \%$ \\
\hline & & More than 1 year ago & 28 & $7.2 \%$ \\
\hline & & Undecided & 0 & $0 \%$ \\
\hline & Total & & 390 & $100 \%$ \\
\hline
\end{tabular}

Table 3 depicts the risk perception of paracetamol use among the participants. Only $21.3 \%$ of the participants read always the patient information leaflet provided by the manufacturer prior to using paracetamol and $53.6 \%$ read it sometimes; $25.1 \%$ never read it at all. Most of them (60.8\%) answered appropriately as to whether paracetamol overdose can cause acute liver failure. Also, $39.5 \%$ of them knew that combining paracetamol with procold constitutes a risky health behaviour. However, $24.9 \%$ of the participants were undecided on this question. Majority (73.6\%) of the participants knew that combining paracetamol intake with alcohol increases the likelihood of developing liver failure. More than half (53.6\%) of the participants do not think self-medication with paracetamol can harm them. Only $23.1 \%$ of the participants knew that people with liver diseases like hepatitis and liver cirrhosis are not to take paracetamol. However, $30.3 \%$ of them were undecided on the question regarding whether those with liver diseases can take paracetamol. Virtually all participants (87.7\%), will never take paracetamol up to six times a day even if symptoms persist.

Table 3. Risk perception of paracetamol use among university of Jos undergraduates.

\begin{tabular}{ccccc}
\hline S/No. & Item & Options & Frequency & Percentage \% \\
\hline & Do you read patient information leaflet & Never & 98 & $25.1 \%$ \\
provided by the manufacturer & Sometimes & 209 & $53.0 \%$ \\
before taking p.c.m? & Always & 83 & $21.3 \%$ \\
Total & & 390 & $100 \%$
\end{tabular}




\section{Continued}

\begin{tabular}{|c|c|c|c|c|}
\hline \multirow{4}{*}{15.} & Can p.c.m overdose & Yes & 237 & $60.8 \%$ \\
\hline & cause acute liver failure? & No & 56 & $14.4 \%$ \\
\hline & & Undecided & 97 & $24.9 \%$ \\
\hline & Total & & 390 & $100 \%$ \\
\hline \multirow{4}{*}{16.} & Is taking procold and p.c.m together risky? & Yes & 154 & $39.5 \%$ \\
\hline & & No & 139 & $35.6 \%$ \\
\hline & & Undecided & 97 & $24.9 \%$ \\
\hline & Total & & 390 & $100 \%$ \\
\hline \multirow{4}{*}{17.} & Does combining p.c.m intake with alcohol & Yes & 287 & $73.6 \%$ \\
\hline & increase the likelihood of developing liver & No & 34 & $8.7 \%$ \\
\hline & failure? & Undecided & 69 & $17.7 \%$ \\
\hline & Total & & 390 & $100 \%$ \\
\hline \multirow{4}{*}{18.} & Do you think self-medication with p.c.m & Yes & 181 & $49.4 \%$ \\
\hline & can harm you? & No & 209 & $53.6 \%$ \\
\hline & & Undecided & 0 & $0 \%$ \\
\hline & Total & & 390 & $100 \%$ \\
\hline \multirow{4}{*}{19.} & Can people with liver diseases for example & Yes & 182 & $46.7 \%$ \\
\hline & hepatitis and liver cirrhosis take p.c.m? & No & 90 & $23.1 \%$ \\
\hline & & Undecided & 118 & $30.3 \%$ \\
\hline & Total & & 390 & $100 \%$ \\
\hline \multirow{4}{*}{20.} & If Symptoms persist can you take p.c.m up & Yes & 48 & $12.3 \%$ \\
\hline & to six times a day? & No & 342 & $87.7 \%$ \\
\hline & & Undecided & 0 & $0 \%$ \\
\hline & Total & & 390 & $100 \%$ \\
\hline
\end{tabular}

\section{Hypothesis}

Null hypothesis: There is no significant difference between courses of study of students and risk perception of paracetamol use.

Table 4 carries information on the observed frequencies used to calculate the expected frequencies. The values obtained from the entire calculation aimed at testing the hypothesis were displayed under the table. Since the calculated chi-square value of 132.5 with the degree of freedom of 2 at significant level of 0.05 is greater than the table value of 5.991, the null hypothesis that, there is no significant difference between courses of study of students and risk perception of paracetamol use was therefore rejected.

Table 4. Cross tabulation of courses of study of students across risk perception of paracetamol use.

\begin{tabular}{ccccc}
\hline F -values. & $\begin{array}{c}\text { Responses elicited from the students regarding whether } \\
\text { taking paracetamol together with procold is risky }\end{array}$ & Total \\
\hline Category of students & Yes & No & undecided & \\
\hline Science students & 142 & 42 & 37 & 221 \\
Arts and humanity students & 12 & 97 & 60 & 169 \\
Total & 154 & 139 & 97 & 390 \\
\hline
\end{tabular}

$X^{2}=132.5 . \mathrm{df}=2$. Table value $=5.991(\mathrm{p}=0.05)$. 


\section{Discussion of Findings}

It was discovered in this study that majority of the participants were females [Table 1]. In a related study done in Sweden by [7], it was reported that the likelihood of a high-risk perception of paracetamol use was higher in women compared with men.

This study also found that most of the participants were science students [Table 1]. A study done on self-medication among university students of Karachi, Parkistan by [12] identified high prevalence of self-medication among educated adults. High prevalence of paracetamol use was also discovered among the participants in this study. [2], conducted a study on perceptions and practice of self-medication among medical students in coastal south India, the researchers stated that self-medication has been on the increase and indiscriminate use of the over-the-counter (OTC) medications is a cause of serious concern for public health agencies globally.

Majority of the participants in this study had taken paracetamol in their life [Table 2]. This finding agrees with the study conducted in Coastal south India where indiscriminate use of over-the-counter (OTC) medications was reported to be a cause of serious concern for public health agencies [2]. The ease with which people access paracetamol over the counter in Nigeria could account for this finding.

This study also found that paracetamol is very easy to get over-the-counter [Table 2]. This finding is similar to that reported by [1] who emphasized that paracetamol is the most widely used over-the-counter and prescription analgesic worldwide. This ease of accessibility could be due to the lack of regulation in the country restricting the sale of paracetamol to trained and qualified professionals. In summary, paracetamol is not a controlled drug in Nigeria and one does not need a prescription from a medical doctor in order to get it.

A significant number of participants had taken paracetamol on 40 or more occasions in their life time [Table 2]. This finding is supported by the finding of the study conducted by [6] on poor knowledge of University students regarding paracetamol; a wakeup call for public health care practitioners. The study reported a significant prevalence of self-medication with paracetamol among the participants. This high intake may be attributed to lack of regulation prohibiting over-the-counter sale of paracetamol by untrained people and ignorance of the adverse effects of paracetamol use on the part of the public.

Most participants in this study did not know the normal daily dose of paracetamol [Table 2]. This finding is in line with what [11] reported; the researcher stated that majority of people have no idea of the maximum daily dose of paracetamol. This lack of knowledge on the normal daily dose of paracetamol could result from over-the-counter purchase of paracetamol by the public often times from unqualified people who knew nothing about the daily dose and adverse effects of paracetamol. Also, the erroneous belief of people that paracetamol is harmless may account for this finding; they may not care about the dose since it 
is not known to cause overt anaphylactic reaction.

More than half of the participants did not think self-medication with paracetamol can harm them [Table 3]. This finding confirmed furtherthe finding by [9] which emphasized that over the counter painkillers are taken most indiscriminately, with potential health hazards and users were found ignorant of their possible adverse effects. Additionally, the finding validated the basic tenet of the Health Belief Model by [13]. This line of thinking may be the result of the fact that people tend to believe that which they can see physically. Because paracetamol abuse damages the liver gradually and the victims do not experience sudden adverse reaction like anaphylaxis, people tend to underestimate its ability to cause serious damage.

Most participants did not know that combing paracetamol with procold is dangerous or risky [Table 3]. This finding is in tandem with the one by [1], who recommended that users need to monitor their intake given that paracetamol is found in many prescription and over-the-counter preparation. This lack of awareness may be the result of the fact that respondents did not always read manufacturer's drug leaflets prior to drug use.

Most participants new that paracetamol overdose can cause acute liver failure [Table 3]. This finding is consistent with the finding by [7] who reported that respondents demonstrated basic awareness of paracetamol use including the potential consequences of overdosing despite purchasing most of their paracetamol over-the-counter. It is common knowledge that excess of everything is bad, perhaps the participants could not have chosen another option.

Majority of the participants did not know that paracetamol is contraindicated in hepatitis and liver cirrhosis [Table 3]. This finding is supported by findings in other studies where a major knowledge gap, low risk perception and high prevalence of self-medication were reported among participants [6] [9]. Not reading manufacture's drug leaflet, purchase of over-the-counter paracetamol especially "counting paracetamol" as it is popularly called and self-medication without the advice of trained health workers could account for this lack of knowledge on the parts of the participants.

More than half of the participants sometimes read the patient information leaflet provided by the manufacturer before taking paracetamol as opposed to always [Table 3]. This implied some degree of carelessness on the parts of participants toward paracetamol. This finding corroborates the finding by [7] in which participants aged 18 - 25 years were reported to express careless attitude toward paracetamol use. [8], stated that people are of the opinion that only harmless medicines are legitimate to be sold without prescription and that over-the-counter medicines usually do not have dangerous side effects; this line of thinking could be responsible for the inconsistency on the parts of the participants with regards to reading patients' information drug leaflets.

There was a significant difference between the courses of study of students and risk perception of paracetamol use [Table 4]. This finding is not in agreement with the finding of the study by [13] who reported lacks of association be- 
tween risk perception and educational status. The finding is also at variance with the result of the study by [14] who also indicated absence of association between educational level and most questions in their study on perception toward appropriate use and adverse effects of paracetamol use among the residents of Al-Ahsa. This dissonance could be blamed on the differences among the various study settings and associated cultural differences. Also, the disagreement could be due to the different inferential statistical method used in the various studies.

\section{Conclusion}

The participants demonstrated poor risk perception of paracetamol use. Also, high prevalence of paracetamol use among participants was discovered, and there was a significant difference between the courses of study of students and risk perception of paracetamol use.

\section{Conflicts of Interest}

The authors declare no conflicts of interest regarding the publication of this paper.

\section{References}

[1] Nelson, P. (2016) Are You at Risk of Acute Liver Failure? Paracetamol Is the "Most Common" Cause of Disease. The Express.

https://www.express.co.uk/life-style/health/755836/symptoms-fatty-liver-disease-sy mptoms

[2] Kumar, N., Kanchan, T., Unnikrishnan, B., Rekha, T., Mithra, P., Kulkarni, V., Uppal, S., et al. (2013) Perceptions and Practice of Self-Medication among Medical Students in Coastal South India. PLoS ONE, 8, e72247. https://doi.org/10.1371/journal.pone.0072247

[3] Karen, W. (2015) Lippincott Illustrated Reviews Pharmacology. 6th Edition, Wolters Kluwer, Alphen aan den Rijn, 456-457.

[4] Katzung, B.G., Susan, B.M. and Trevor, A.J. (2009) Basic and Clinical Pharmacology. 11th Edition, McGraw-Hill, New York, 60, 635.

[5] Matok, I. (2018) Prolonged Acetaminophen Use during Pregnancy Linked to Increased ASD (Autism Spectrum Disorder) and ADHD (Attention Deficit and Hyperactive Disorder) AJE.

[6] Maham, T. and Fakhar, U.D. (2017) Poor Knowledge of University Students Regarding Paracetamol; a Wakeup Call for Public Healthcare Practitioners. Cogent Medicine, 4, Article ID: 1320848. https://doi.org/10.1080/2331205X.2017.1320848

[7] Hakonson, H. and Hedenrud, T. (2017) A Population-Based Study of Risk Perceptions of Paracetamol Use among Swedes-With Special Focus on Young Adults. Pharmacoepidemiology and Drug Safety, 26, 992-997. https://doi.org/10.1002/pds.4238

[8] Panero, C. and Persico, L. (2016) Attitudes toward and Use of Over-the-Counter Medications among Teenagers: Evidence from an Italian Study. International Journal of Marketing Studies, 8, 65-75. https://doi.org/10.5539/ijms.v8n3p65

[9] Wilinski, J., Leechowicz, M., Kameczura, T., Glowacki, M., Kamecura, A., Chrapus- 
ta, A. and Wilinski, B. (2015) Nonsteroidal Anti-Inflammatory Drugs and Paracetamol in Self-Therapy of Various Disorders in Students of Different Fields of Study. Folia Medica Cracoviensia, 55, 49-59.

[10] Herbert, A.O., Josephat, M.C., Agozie. C.U., Christopher, B.E. and Ikenna, K.N. (2012) Paracetamol Use (and/or Misuse) in Children in Enugu South-East Nigeria. BMC Pediatrics, 12, 103. https://doi.org/10.1186/1471-2431-12-103

[11] Moore, A. (2016) What Is the Point with Paracetamol?

[12] Zafar, S.N., Syed, R., Waqar, S., Zubairi, A.J., Vaqar, T., Shaikh, M., Saleem, S. et al. (2008) Self-Medication amongst University Students of Karachi: Prevalence, Knowledge and Attitudes. Journal of Pakistan Medical Association, 58, 214.

[13] Becker, M., Haefner, D.P., Kasl, S.V., Kirscht, J.P., Maimam, L.A. and Rosenstock, I.M. (1974) Selected Psychosocial Models and Correlates of Individual Health Related Behaviours. Medical Care, 15, 27-46. https://doi.org/10.1097/00005650-197705001-00005

[14] Boudjemai, Y., Mbida, P., Potinet-Pagliaroli, V., Geffard, F., Leboucher, G., Brazier, J.L. and Charpiat, B. (2013) Patients' Knowledge about Paracetamol (Acetaminophen): A Study in a French Hospital Department. Annales Pharmaceutiques Françaises, 71, 260-267. https://doi.org/10.1016/j.pharma.2013.03.001 